\title{
RESENHAS
}

\section{ESPAÇOS DA LINGUAGEM NA EDUCAÇÃO}

Mary Julia Martins Dietzsch (org.)

São Paulo: Humanitas/FFLCH/NSP, 1999, 195p.

Uma bela composição de linguagem visual anuncia e enriquece os diversos artigos que compõem o livro: a educação se abre a distintas linguagens que, por sua vez, forçam a passagem por novos espaços na esfera educacional.

$\mathrm{Na}$ apresentação, Mary Julia Martins Dietzsch, organizadora do livro, apresenta e contextualiza os artigos, frutos de seminário realizado em 1998 pela área temática Linguagem e Educação, ligada ao Programa de Pós-Graduação da Faculdade de Educação da Universidade de São Paulo - Feusp, com o apoio do Conselho Nacional de Desenvolvimento Científico e Tecnológico CNPq. O interesse e a preocupação de refletir sobre as relações entre linguagem e educação, da perspectiva de uma visão dialógica que constrói lugares, caminhos e cenas "criados com e pela linguagem, na educação", são o traço comum do seminário e dos textos.

Os dois artigos de abertura focalizam o pensador russo Mikhail Bakhtin, cujas idéias, difundidas no Brasil a partir dos anos 70, provocaram novas reflexões acerca da língua, da linguagem, da literatura e criação artística e, por extensão e convergência de questões, abriram caminho para discussões entre diferentes áreas de conhecimento.

O primeiro artigo, "Mikhail Bakhtin: o discurso na vida e o discurso na arte", de Beth Brait, destaca aspectos fundamentais do pensamento deste "autor" - conceito polêmico em que a idéia de "autoria" atravessa todo o pensamento bakhtiniano - no âmbito do estudo biográfico e bibliográfico que apresenta. Chama a atenção para o que considera mais interessante e desafiador para a compreensão da obra do pensador: a relação entre a vida e sua produção escrita. $\bigcirc$ "indivíduo" Bakhtin "prepara o autor" e "erige a personagem" através da relação intensa e coerente entre vida e obra do homem que busca compreender a si, ao outro e ao mundo na e pela linguagem.

O ponto central do artigo de Irene Machado é a relação entre o conceito de texto e de gêneros, como o próprio título indica: "Texto \& gêneros: fronteiras". A partir dos estudos de $M$. Bakhtin sobre a concepção de gênero, a autora abre a possibilidade de a cultura ser lida como texto, do ponto de vista semiótico.

O modo pelo qual inicia sua reflexão pode gerar controvérsias e discussão: "Na era da informação tudo é texto". Quaisquer "variados arranjos" cuja composição tem o objetivo de "informar, comunicar, veicular sentidos são texto"; o que afasta, portanto, a exclusividade e primazia da palavra signo verbal oral e escrito - como determinante do conceito e natureza do texto. Ao recorrer à etimologia da palavra - "texto é tecido", construído não pela hierarquização dos fios mas por sua combinação "enredada" - a autora reforça o hibridismo textual: seu caráter de "produto cultural híbrido" compõe as diferenças em vez de separá-las, com vistas à construção de sentido.

Parte, em seguida, para uma série de reflexões sobre a concepção de linguagem e gêneros do discurso, e noções básicas de semiótica. São citadas idéias de C. S. Pierce e sua noção de signo; D. R. Olson e a discussão sobre a relação entre enunciado - fase oral - e letramento - fase textual; V. N. Volochinov e seu estudo sobre a entoação e a enunciação. Tais idéias apóiam e esclarecem a questão fundamental do artigo: a concepção de gêneros do discurso, fundada na concepção dialógica da linguagem, com a "valorização da pluralidade", de "misturas", relacionadas à concepção de "texto-tecido" constituído como uma "tela dialógica". 
O uso escolar dessas noções de texto, gênero e discurso é comentado com uma dose de preocupação didático-pedagógica. A autora considera que ocorrem sérios equívocos, muitas vezes causados por "fragilidade teórica" sobre tais noções e, a seguir, esclarece a tênue fronteira entre elas: "Texto é modalidade composicional; produto comunicativo; unidade de informação vinculada à vida interativa. Gêneros são articulações discursivas que organizam e definem a textualidade. Os gêneros são inconcebíveis fora do texto; sem os gêneros, o texto se esfarela". Com isso, rejeita a idéia de "classificação" - não existe gênero no singular, "gêneros vivem sobre fronteiras".

Finalmente, o artigo discute a questão da entoação no texto, na vida, na cultura: "o contato entre vida e enunciado, modulado pelo gênero, imprime um tom, uma entoação expressiva à enunciação". Para exemplificar, comenta o texto de Millôr Fernandes, "A vaguidão específica", em que o leitor, sem a possibilidade de conhecer o assunto do diálogo entre a patroa e a empregada - o não-dito - lê o texto e o compreende pela entoação. Esta é, portanto, social, e seu sentido aponta uma dupla direção: ao ouvinte-interlocutor e à cultura. Assim, Irene Machado termina seu texto, e o leitor encontra-se às voltas e enredado - entretecido e entretido - com tantas noções desafiadoras à compreensão desse mundo feito de tantas linguagens.

O título do artigo de Maria Thereza Fraga Rocco, "Entre a oralidade e a escrita: reflexões esparsas", já predispõe o leitor para o encontro com idéias que apontam a variedade de novos espaços abertos à reflexão sobre a oralidade e a escrita, em grande foco atualmente. A epígrafe de Galileu modula essa disposição do leitor: em tom de perplexidade amorosa e cúmplice, o sábio reforça uma paixão pela escrita, "vinte pequenos caracteres numa folha de papel" capazes de transportar idéias a distância no tempo e no espaço.

As quatro partes de que se compõe o artigo organizam de modo didático, esclarecedor e atraente algumas das questões que devem ser estudadas, discutidas e compreendidas em seus devidos lugares: áreas específicas do conhecimento e determinados pontos de vista, para não gerar imprecisões conceituais e terminológicas. O grande interesse e preocupação de Rocco é questionar certas noções cristalizadas, levantar aspectos deixados de lado e destacar outros sob novo ângulo de visão, mantendo sempre um caminho de mão dupla entre o oral e o escrito, histórica e culturalmente situados.

A primeira parte, "Da mão que liberta a palavra ao gesto indicador", propõe um recuo no tempo com a citação de Gregório de Nisa que, no ano de 379 d.C., percebeu essa "mão que liberta a palavra": as mãos chamaram para si o cargo da alimentação "e libertaram a boca para o serviço da palavra". A mão, espécie de "utensílio original", instrumento de sobrevivência, que tantas conquistas assegurou ao ser humano, entra em uma espécie de comunhão com a fala e a linguagem, e possibilita o "gesto humano único: o gesto indicador que a criança pequena faz, gesto que indicia no homem o surgimento da consciência e da própria linguagem". A seguir, a autora refere-se ao trabalho do filósofo vietnamita Tran Duc Thao, de 1973, o qual, ao estudar a linguagem e a inteligência da criança, contestando os estudos americanos "fortemente mecanicistas", analisou esse gesto de indicação através da comparação entre o desenvolvimento de um chimpanzé e de um bebê. Na criança, o gesto indicador inaugura "uma atividade cerebral-cognitiva única, exclusiva do gênero humano" e é seguido de um "olhar também indicador"; a criança e o outro, "objeto de seu desejo", revelam-se nesse "olhar histórico, indicador e consciente". Segundo o pesquisador, esse é o momento da origem da consciência e da linguagem.

Uma breve passagem pelo surgimento e evolução da escrita é apresentada ao leitor na segunda parte, em que alguns conceitos e hipóteses são expostos: destaca a obra de Ignace Gelb, História da escrita, publicada na década de 50, e passa em revista as idéias de D. Olson, Léroi- 
Gourhan, W.J. Ong, H. Sinclair, E. Ferreiro, Luria, sempre com a preocupação de situá-las e estabelecer relações entre elas. A reflexão constante e a atitude de sempre formular novas perguntas a teorias cristalizadas afastam o perigo da cristalização de verdades entre a teoria e a prática.

Esses caminhos, itinerários em mão dupla, Rocco desenvolve na terceira e na quarta e última parte do artigo. Entre alguns aspectos relevantes, destaca a "dimensão lingüística do oral e da escrita", e a importância da "interação" para a análise de uma fala ou de um diálogo. As idéias de Bakhtin, os estudos de L. S. Vygotsky sobre a "fala egocêntrica", a "fala interior" e a "fala exteriorizada" da criança pequena são lembrados nas relações entre a oralidade e a escrita no processo de constituição da linguagem.

Finalmente, essas reflexões esparsas e contíguas chegam a "O tempo da eletrônica: a geração de um texto híbrido". Da mesma maneira como a invenção da escrita, o novo que ora se apresenta na cultura, tanto erudita quanto de massa, causa temores e provoca reações as mais diversas e adversas. A invenção do códice que substituiu o rolo de difícil leitura, o cinema falado que deixou para trás o cinema mudo, o advento da televisão que paira como uma ameaça a tantas artes que insistem em sobreviver - e sobreviverão... -, as novas comunicações em redes eletrônicas, o texto via internet, tantas formas que interagem e convivem umas com as outras apontam novas relações entre a oralidade e a escrita. É o surgimento de um "texto híbrido", conclui a autora, "oralizado por escrito", na tentativa de reproduzir o gesto e a entonação próprios de uma fala original e fundadora.

$\bigcirc$ artigo de Maria Helena Martins intitula-se "Encruzilhada de leituras", e através dele o leitor poderá questionar-se e duvidar ele próprio do ato que realiza: o que é mesmo Ler? O que é mesmo ser um Leitor? O interesse recai principalmente sobre o como se dá a leitura do homem comum de nossa cultura, na tentativa de compreender esse processo rico e complexo de atribuir sentidos a tudo o que apreendem nossos olhos. texto origina-se de um projeto de pesquisa coordenado pela autora, cujo relatório completo, datado de 1993, encontra-se no Centro de Pesquisas para a Educação e Cultura Cenpec -, em São Paulo, que o patrocinou. Sua "motivação mais imediata" surgiu de sugestão do pesquisador francês Jacques Leenhardt, coordenador do projeto Existe-t-il un lécteur européen?, realizado na França em 1989.

Nos comentários sobre a análise dos dados das duas entrevistas realizadas com 12 jovensadultos e adolescentes - Maria Helena Martins problematiza e aprofunda, de forma atraente para o leitor, as questões que dizem respeito tanto ao significado da concepção de leitura e suas práticas, no discurso dos entrevistados e no discurso da cultura em geral, quanto à forma pela qual os entrevistados falam durante o processo de pesquisa, em que um vínculo é construído, de suas leituras verdadeiras, de suas concepções reais. Há uma aparente contradição, afirma a pesquisadora, entre essas dimensões da leitura: nenhum entrevistado considera-se leitor, a leitura está sempre ligada ao livro e este à escola. Ao lerem o livro "para a escola" e não para eles próprios, consideram-se não-leitores; como o livro para eles é o "objeto de cultura por excelência", e esta é importante e "de alto nível", distanciada de seu mundo, "fora da vida", sentem-se distanciados e afastados da leitura, que é parte da cultura.

Em seguida, a pesquisadora examina as relações que os jovens entrevistados estabelecem com as outras linguagens, sobretudo com a imagem e seu "privilégio semiológico", na televisão e no cinema, nas revistas e shows ao vivo. Para eles, "ler se refere à palavra escrita", à obrigação, a "muitos livros", a saber das coisas importantes, a um esforço e exigência que lhes dão a "sensação de perda de tempo", enquanto "as coisas acontecem". Toda leitura de texto escrito está ligada à função de tarefa escolar e não ao escrever. Martins aponta aí a ausência de uma mediação para a leitura, que os ajudaria a compreender "por que, quando e como" acontece o processo de ler. 
Na segunda entrevista, os jovens deveriam apresentar sua releitura da revista Veja, entregue pelos pesquisadores, e comentar a reedição proposta por estes. Pelos comentários, a pesquisadora percebe que há "incoerência entre procedimentos observados e relatados e o discurso sobre a importância do texto"; este é valorizado em um nível genérico. Os jovens falam de sua leitura de fotos, de imagens, charges, propaganda, gráficos, e o texto vem em segundo plano. É o que ela chama de "(re)leitura em flashes", evidenciada no próprio discurso deles, fragmentado, elíptico, com entrelinhas ocultas entre o dito e o não-dito, em um vai-e-vem temporal, "clipado". Acontece uma "dinâmica caleidoscópica redimensionando o tempo e o espaço da leitura", o que reforça uma idéia de ilusão de liberdade contrapondo-se à disciplina. A TV e o controle remoto, a internet e o mouse fazem parte da construção desse novo processo de leitura, uma "legibilidade" ligada à "conquista do leitor apressado".

Finalmente, Martins assinala a importância de se "reavaliar a relação entre diferentes linguagens e suas leituras", sobretudo a textual e a pictórica. Aponta a possibilidade de o "assédio das linguagens não-verbais" propiciar outros caminhos aos jovens leitores para reconhecerem e se apropriarem da linguagem verbal.

Martins realça ainda outros possíveis caminhos do processo em que ocorre a leitura: nas entrelinhas, nos desvãos entre o dito e o não-dito, numa espécie de "dimensão mental da leitura", que valoriza o como se lê, no qual residiria o significado atribuído ao convívio das várias linguagens.

O artigo de Mary Julia Martins Dietzsch, "Imagens de leitura e escrita no diálogo com professoras", reflete sobre o trabalho desenvolvido com três professoras de classes iniciais do ensino fundamental, da rede pública da cidade de São Paulo, em projeto realizado entre 1993 e 1998 , com o apoio do CNPq, do qual participaram professores, pesquisadores e alunos bolsistas da Faculdade de Educação da USP.

A questão principal refere-se às relações entre o discurso e a prática das professoras, enca- minhada por algumas perguntas norteadoras do trabalho de pesquisa na observação em sala de aula: a organização do ambiente na classe propicia o diálogo e um conhecimento partilhado? Que concepção de linguagem e de conhecimento fundamentam a ação do professor?

Inicialmente Dietzsch situa cada uma das professoras e comenta aspectos observados nas respectivas salas de aula. Dentre tais observações, algumas chamam mais a atenção. Em primeiro lugar, o reconhecimento de um saber mínimo, necessário e suficiente ao ofício do magistério, relacionado a certo "utilitarismo" da profissão, baseado na possibilidade reduzida de ascensão social ou econômica que ela proporciona. Como conseqüência, a desvalorização da profissão, do próprio professor e do aluno.

Em seguida, outros aspectos a ser destacados são:

- ritual de rotina repetitiva, como se fosse um mesmo jogo a ser jogado diariamente dirigido pela fala monológica do professor;

- a compreensão parcial, algumas vezes equivocada, do papel docente, em que prevalece uma "visão assistencialista", e o vínculo pelo afeto estabelecido à margem do processo de conhecimento;

- uma prática de ensino através do texto, na qual a rigidez com que é seguida a programação, sem a participação de toda a classe, e o modo de retirar conteúdos do texto lido indicam "uma concepção de leitura moralizadora em que possíveis ensinamentos ou o pretexto para outras atividades se fazem mais importantes do que a apreciação do próprio texto";

- uma distância entre o que a professora acredita que faz em sala de aula e a observação do que realmente realiza. A partir daí, o fato de que a participação em cursos ou a leitura de textos de teor prescritivo que enfoquem novas teorias e metodologias de ensino não garantem a apropriação desses 
novos caminhos e a transformação da prática do professor, por ele tão almejada. Muitas vezes, o que acontece é a verbalização de terminologias e conceitos, o que faz o professor ter a sensação de pertencer às modernas teorias;

- uma rigidez disciplinar e no encaminhamento das atividades propostas conduz à participação e inclusão dos me/hores na classe e à exclusão e segregação dos menos interessados ou com maiores dificuldades de caráter pedagógico.

A pesquisadora ressalta a preocupação de focalizar a "organização do espaço/tempo na sala de aula", e o entendimento da aula como acontecimento, a partir de um olhar que desnaturaliza, o que em geral acontece como hábito e rotina escolar. Nesse sentido, a parte intitulada "As professoras e o construtivismo: desejo de pertença" desenvolve uma reflexão sobre tais concepções de espaço e tempo da aula, a partir dos conceitos das três professoras, que permeiam a crença de estarem fazendo o melhor e a ação propriamente dita em sala de aula.

Um momento bastante delicado da pesquisa é aquele em que se percebe uma espécie de desconstrução do fazer pedagógico e, ao mesmo tempo, o despertar do desejo da continuidade renovada de uma prática - um passo adiante sem desgarrar-se dos passos dados e sem perder o caminho para onde. Duas ocorrências foram fundamentais para essa nova compreensão por parte das professoras: a projeção do vídeo das aulas filmadas, em que as imagens distanciadas e mediadas possibilitaram que se enxergassem sob outro ângulo e discutissem o que viram; a leitura de textos de obras literárias, como Infância, de Graciliano Ramos, que aborda a aprendizagem das primeiras letras, e Os componentes da banda, de Adélia Prado, em que ela registra suas impressões como professora.

No artigo "Adolescentes e livros: a mediação da escola", Cláudia Arruda Campos e Maria
Lúcia Zoega de Souza dão uma contribuição importante às tentativas de solucionar o quase impasse da crise da leitura entre os jovens: ou é considerada nula, pouca e insuficiente, ou equivocada, mal escolhida e não valorizada.

A partir da concepção de formação do leitor como "o desenvolvimento da capacidade de retirar da leitura mais e mais elementos significativos que se incorporem a outros e mais outros, fundamentando o processo ininterrupto de crescimento emocional, intelectual e social", algumas questões polêmicas são colocadas:

- livro centraliza, ainda hoje, as atividades de ensino destinadas à formação do leitor?

- que espécie de mutação no processo de ler vem se produzindo, desde a invenção da tipografia por Gutemberg no século XV?

- de que modo os avanços tecnológicos, sobretudo na área da informática com a expansão da internet, interferem na constituição do leitor?

- entre os que profetizam a morte do livro e os que proclamam sua eterna vitalidade, como torná-lo vivo nesse espaço em conflito de posições apaixonadas?

- os leitores de hoje lêem da mesma forma que aqueles dos primórdios da leitura ocidental?

- para que ensinar a leitura aos jovens escolares de hoje? Se a resposta for convincente, uma nova pergunta se impõe: é possível? de que modo?

Posicionando-se, com convicção, em favor da importância e necessidade da leitura de livros pelos jovens, as autoras apresentam argumentos sólidos e exemplos de obras diversas que podem despertar-Ihes o interesse e o gosto, no presente e, quem sabe, no futuro. Alguns livros, segundo elas, lidos na infância ou na adolescência, poderão ter alguma repercussão em outro momento da vida. 
Enfatizam o interesse do jovem pela ficção autobiografia, policial, aventuras, mistério e terror - e essa espécie de "necessidade" e "desejo" da literatura pelo ser humano evocando as concepções de Antonio Candido e de José Paulo Paes, para quem a obra literária é uma das formas mais elaboradas para a humanização do ser humano e a leitura de um bom livro exige uma atenção especial do leitor.

Finalmente, abordam questões polêmicas como o caso das adaptações, o critério de adequação à faixa etária, a função da leitura de entretenimento e o insubstituível papel do mediador entre o jovem e o livro, sobretudo no que diz respeito à leitura escolar.

O artigo de Vera Lúcia Marinelli, "Os telejornais em sala de aula: sugestões para o ensino de português", apresenta propostas e, ao mesmo tempo, discute algumas idéias importantes quanto à presença e utilização da TV nas atividades escolares. Constata que a TV freqüenta pouco a sala de aula por três motivos: a ausência de um espaço de reflexão na escola sobre a importância dos meios de comunicação na formação do cidadão; o temor de que as novas tecnologias possam substituir a presença do professor; a concepção de que a TV seja um "gênero menor" e responsável pela baixa qualidade da expressão lingüística de falantes e ouvintes.

Vera Lúcia dirige-se aos professores com uma proposta prática de atividade com os telejornais em sala de aula. Apresenta sugestões para sua análise, subsídios sobre o funcionamento de diferentes telejornais e propostas de atividades a partir da macro e microestrutura do telejornal.

Conclui que a presença da TV na sala de aula contribui para a tão propalada construção da cidadania da criança e do jovem, se considerada como um meio de comunicação e não como substituição do professor. Ela deve ser entendida como um instrumento didático-pedagógico e não como panacéia para atrair, motivar e interessar a criança e o jovem durante as aulas.

Finalmente o artigo de Amaury Cesar Moraes, "Uma crítica da razão pedagógica a partir da leitura d' O Atenel', encerra o livro, concluindo o trabalho de "desestabilização da tradicional cena descrita nos discursos pedagógicos", como bem aponta Celso Favaretto na contracapa.

Morais parte da constatação de que a idéia de formação - e seus correlatos reformar, transformare deformar - subjaz à concepção de educação desde os tempos antigos até os modernos, e atinge tanto os educandos quanto os educadores.

Sucessiva e alternadamente, as propostas pedagógicas se apresentam em sua face mais ou menos conservadora; algumas vezes, até, com a pretensão de ser revolucionárias e transformadoras. A formação do educando visaria sempre a um bem, acima de qualquer suspeita, devendo ser concebida, justificada e legitimada pelos "próprios padrões de formação": o discurso pedagógico encarnado pelos mestres.

Aqui reside o tema central do artigo: "o discurso pedagógico tem essa dimensão que justifica e legitima a pedagogia, institui o pedagogo como portador de um saberque é monopólio daquele que educa o educador".

À pergunta sobre a quem caberia a tarefa de formar, o autor responde que atualmente cabe à escola, e não mais ao mestre ou ao próprio educando. Passa, em seguida, à análise de aspectos do romance autobiográfico de Raul Pompéia, mostrando que a obra constitui um "discurso pedagógico em si", estruturado em conjunto com outros tantos, a partir do narrador.

Morais aponta algumas características do romance de formação e desenvolve idéias acerca do conceito de instituição, no sentido de demonstrar que o internato "governado" por Aristarco era uma instituição escolar concebida como um microcosmo da sociedade, na qual o educando deveria se formar. Em nome desta, e sob suas leis, a escola tinha o dever de formar moralmente seus alunos para servi-la e perpetuála. Assim, a escola era concebida como instituição orientada não mais para a transmissão de conhecimentos, mas para o objetivo de formar o cidadão; em seus anos de internato o aluno 
submetia-se a uma formação moral acima da científica e técnica.

Ao final do artigo, o autor situa a escola brasileira de final do século XIX, configurada no Ateneu, como de inspiração grega e iluminista, com os traços de influência positivista, segundo a qual aprender a escolhere julgarera o imperativo da razão.

A partir da relação entre escola e Estado, e educação e sociedade, indaga o autor: "como pensar em uma educação revolucionária e aproximar-se da sociedade", se preparar para a vida significa servir a esta?

Ana Maria Lima Teixeira

Doutoranda em Linguagem e Educação pela Faculdade de Educação da USP maroki@terra.com.br 